\section{Response of Young Olive Trees to Sodium and Boron Excess in Irrigation Water}

\author{
M. Benlloch, F. Arboleda, D. Barranco, and R. Fernández-Escobar \\ Departamento de Agronomía, Universidad de Córdoba, Apartado 3048, \\ 14080 Córdoba, Spain
}

Additional index words. Olea europaea, salinity, cultivars

\begin{abstract}
The influence of sodium and boron excess in the irrigation water on shoot growth and on the distribution of these elements within various leaf types was studied on rooted olive cuttings (Olea europaea L.). 'Lechín de Granada' was more tolerant than 'Manzanillo' to sodium excess, as indicated by greater shoot growth and lower accumulation of sodium, especially in the young leaves. 'Picual' was more tolerant to boron than 'Manzanillo', with less accumulation in adult leaves. The results suggest the avoidance of toxicity by an ionic exclusion mechanism that is more effective in some cultivars than others. Also, the results reveal cultivar differences in the tolerance of olive to sodium and boron excess in the culture medium.
\end{abstract}

The saline tolerance range of crops is very wide, extending from very sensitive species, such as beans, to highly tolerant ones, such as barley and cotton (Maas and Hoffman, 1977). Olive has been described as a tolerant species that may be cultivated in saline soils where other fruit trees cannot grow (El Gazzar et al., 1979). However, some symptoms of toxicity and cultivar differences in susceptibility to high concentrations of salts have been described (Hartmann et al., 1966). Bongi and Loreto (1989) have demonstrated that marked saline stress can produce accumulation of sodium and chloride in olive leaves, decrease growth, alter photosynthesis, and cause morphological changes in the leaves. Little is known about specific ionic toxicity in olive. El-Gazzar et al. (1979) described the olive as a species tolerant to irrigation with dilute sea water and very sensitive to irrigation with wastewater. 'Manzanillo' has been described as very resistant to high concentrations of chlorides in irrigation water (Robinson, 1987). According to Hansen (1945), olive is more resistant to an excess of boron than peach, apple, plum, or apricot. Hansen suggested that the differences are due

Received for publication 10 July 1990. This research was supported by Ministerio de Educación y Ciencia Project PB86-0545. The cost of publishing this paper was defrayed in part by the payment of page charges. Under postal regulations, this paper therefore must be hereby marked $a d$ vertisement solely to indicate this fact. to minimal accumulation of boron in olive leaves when grown on soils with high concentrations of this element.

We report the behavior of young olive plants exposed to high concentrations of sodium and boron in the irrigation water. The goal of this research was to characterize some physiological traits that would permit the selection of cultivars tolerant to an excess of those elements either in the soil or in the water.

The experiments were carried out in a greenhouse between January and June in the range of 18 to 30C. Artificial lighting was provided in winter to obtain a 14-h photoperiod. Two experiments were performed to days after the initiation of treatments.

*,***Linear (L) at $P=0.05$ or 0.001 , respectively. study toxicity of sodium and boron. Mistrooted 'Manzanillo' and 'Lechín de Granada' cuttings were used for the studies on sodium, and 'Manzanillo' and 'Picual' for those with boron. These cultivars are adapted to different growing areas in Spain.

After 2 months under mist, individual rooted cuttings were transferred to 1.5-liter plastic pots containing 2 river sand : 1 peat. Before the initiation of treatment and after 30 days of acclimation, the cuttings were pruned to a single shoot per plant.

Sodium was applied in the form of $\mathrm{NaCl}$ dissolved in the irrigation water at $0,20,40$, and $100 \mathrm{~mm}$. There were four plants (replications) per treatment. The plants were watered twice a week with $250 \mathrm{ml}$ of the corresponding solution. Once a week, at the time of watering, a commercial fertilizer, Hakaphos 15.11.15 (BASF Española, Sociedad Anónima) containing 15\% N, 4.8\% P, $12 \% \mathrm{~K}, 0.8 \% \mathrm{Mg}, 9 \% \mathrm{~S}, 0.03 \% \mathrm{~B}, 0.1 \%$ $\mathrm{Mn}, 0.06 \% \mathrm{Zn}$, and $0.004 \% \mathrm{Mo}$, was added at a ratio of $1 \mathrm{~g} \cdot \mathrm{liter}^{-1}$. The experiment lasted 57 days; during this time, shoot length was measured on five dates. At the end of the experiment, potassium and sodium contents were analyzed in young leaves, located in the apical part of the shoot, in the expansion phase and in mature leaves located in the central part of the shoot, both types having been formed during the experiment.

Boron was applied as boric acid dissolved in the irrigation water solution at 0,20 , and $40 \mathrm{mg} \cdot \mathrm{liter}^{-1}$. There were five plants (replications) per treatment. During the first 80 days, the plants were each watered with 250 $\mathrm{ml}$ once a week; thereafter, watering was increased to twice a week. In all cases, watering with boron was alternated with

Table 1. Effect of sodium chloride concentration in the irrigation water on $\mathrm{K}$ accumulation and the $\mathrm{K}$ : Na ratio in young and mature leaves of 'Manzanillo' and 'Lechín de Granada' olive cuttings 57

\begin{tabular}{|c|c|c|c|c|c|}
\hline \multirow[b]{2}{*}{ Cultivar } & \multirow[b]{2}{*}{$\begin{array}{l}\mathrm{NaCl} \\
(\mathrm{mM})\end{array}$} & \multicolumn{2}{|c|}{ Young leaves } & \multicolumn{2}{|c|}{ Mature leaves } \\
\hline & & $\frac{\mathrm{K}}{\left(\mu \mathrm{mol} \cdot \mathrm{g}^{-1} \text { fresh wt }\right)}$ & $\mathrm{K}: \mathrm{Na}$ & $\frac{K}{\left(\mu \mathrm{mol} \cdot \mathrm{g}^{-1} \text { fresh wt }\right)}$ & $\mathrm{K}: \mathrm{Na}$ \\
\hline \multirow[t]{4}{*}{ Manzanillo } & 0 & 234.6 & 29.9 & 253.3 & 24.2 \\
\hline & 20 & 240.4 & 11.2 & 258.0 & 3.6 \\
\hline & 40 & 239.1 & 4.2 & 223.9 & 2.4 \\
\hline & 100 & 221.2 & 1.0 & 227.5 & 0.8 \\
\hline Significance & & NS & $\mathrm{L}^{* * *}$ & NS & $\mathrm{L}^{* * *}$ \\
\hline \multirow[t]{4}{*}{ Lechín de Granada } & 0 & 185.0 & 17.2 & 207.2 & 23.4 \\
\hline & 20 & 203.2 & 16.6 & 203.7 & 5.6 \\
\hline & 40 & 208.6 & 12.0 & 202.1 & 3.2 \\
\hline & 100 & 220.8 & 3.5 & 184.2 & 1.8 \\
\hline Significance & & $\mathrm{L}^{*}$ & $\mathrm{~L}^{* * *}$ & NS & $\mathrm{L}^{* * *}$ \\
\hline
\end{tabular}



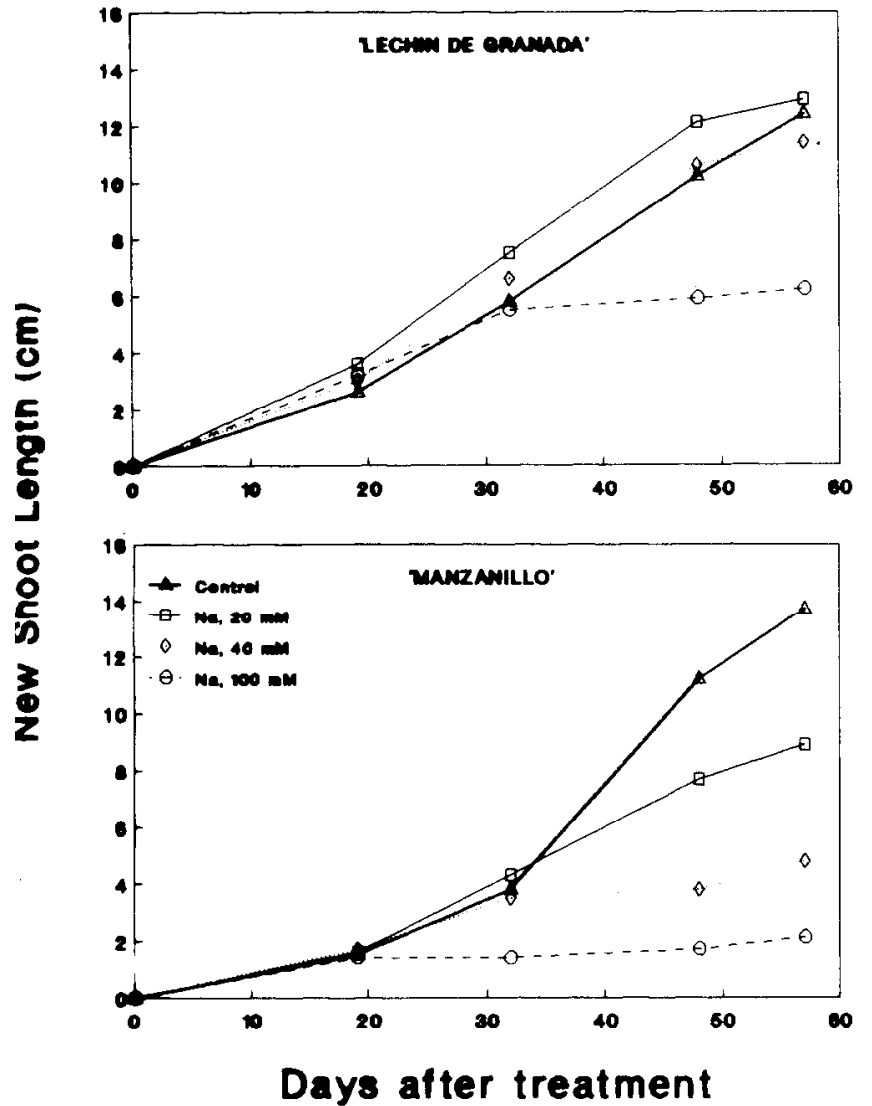

Fig. 1. Shoot length of olive cuttings in response to $\mathrm{NaCl}$ concentration in the irrigation water. Each determination is the average of four one-plant replications.

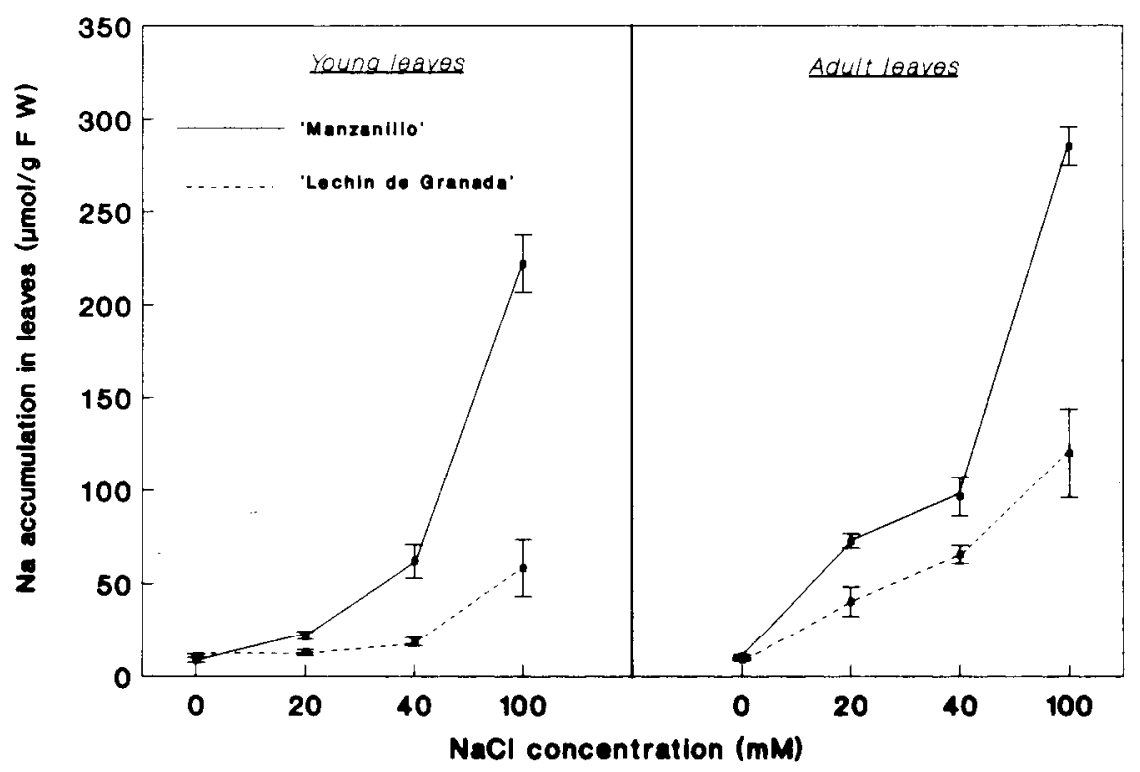

Fig. 2. Effect of $\mathrm{NaCl}$ concentration in the irrigation water on the accumulation of $\mathrm{Na}$ in young and mature leaves of 'Manzanillo' and 'Lechín de Granada' olive cuttings measured 57 days after the initiation of treatment. The vertical bars indicate the standard error of four replications.

watering with a nutrient solution plus the corresponding boron concentrations. Hoagland solution modified in the following way was used as the base nutrient solution: 2.5 $\mathrm{mM} \mathrm{Ca}\left(\mathrm{NO}_{3}\right)_{2}, 1.0 \mathrm{~mm} \mathrm{MgSO}_{4}, 0.25 \mathrm{~mm}$ $\mathrm{Ca}\left(\mathrm{H}_{2} \mathrm{P} \mathrm{O}_{4}\right)_{2}, 12.5 \mu \mathrm{M} \mathrm{H}_{3} \mathrm{~B} \mathrm{O}_{3}, 1.0 \mu \mathrm{M}$ $\mathrm{MnSO}_{4}, 1.0 \mu \mathrm{MnSO}_{4}, 0.25 \mu \mathrm{M} \mathrm{CuSO}_{4}$, $0.2 \mu \mathrm{M}\left(\mathrm{NH}_{4}\right)_{6} \mathrm{M} \mathrm{O}_{7} \mathrm{O}_{24}$, and $10 \mu \mathrm{M}$ Fe-eth- boron content in mature and young leaves was analyzed as described below.

Potassium and sodium contents were analyzed by atomic absorption spectrophotometry. The extraction of these cations was carried out as described by Benlloch et al. (1989). Boron content was determined by calorimetry according to Naftel's method, as described by Jackson (1958). The leaves were washed in deionized water and then calcined. The ash was dissolved in $0.1 \mathrm{~N} \mathrm{HCl}$ and the extract used to determine boron content.

Effect of $\mathrm{NaCl}$ on plant growth. Sodium chloride decreased shoot growth more in 'Manzanillo' than in 'Lechín de Granada' (Fig. 1). In 'Manzanillo', all treatments had a negative effect on growth, being more noticeable the higher the concentration of $\mathrm{NaCl}$ in the irrigation water. In 'Lechín de Granada', inhibition was only observed with the 100-m $\mathrm{m}$ concentration. The decrease in growth at this concentration was similar to the one found for 'Manzanillo' with the 40mu concentration.

The higher the concentration of $\mathrm{NaCl}$ in the irrigation water, the higher the accumulation of $\mathrm{Na}$ in the leaves of the rooted olive cuttings (Fig. 2). This was more marked in adult leaves than in young growing ones. Under similar saline stress conditions, 'Manzanillo' always accumulated more $\mathrm{Na}$ in leaves than 'Lechín de Granada'. Under moderate saline conditions, Na concentrations in young leaves from 'Lechín de Granada' were similar to those found for plants not subjected to stress. At $100 \mathrm{~mm} \mathrm{NaCl}, \mathrm{Na}$ accumulated in young leaves of 'Lechín de Granada' at levels similar to those found for young 'Manzanillo' leaves treated with $40 \mathrm{~mm} \mathrm{NaCl}$. No symptoms of leaf toxicity were observed during the 57 days of the experiment.

The K : Na ratio in leaves 57 days after the start of treatment showed a linear relationship that was inversely proportional to the $\mathrm{NaCl}$ concentrations in the irrigation water (Table 1). This effect was more marked in 'Manzanillo' than in 'Lechín de Granada' and in adult leaves than in young ones. Under moderate saline conditions, the $\mathrm{K}: \mathrm{Na}$ ratio in young 'Lechín de Granada' leaves was higher than in 'Manzanillo', their value being similar to the ones found for the controls. This relationship is due, in part, to the low levels of $\mathrm{Na}$ in the leaves of these plants and in part to an enhanced accumulation of Kin young 'Lechín de Granada' leaves (Table 1). A similar behavior has been described for some nonhalophyte species, such as $\mathrm{He}$ lianthus annus L. (Lessani and Marschner, 1978) and Trifolium alexandrinum L. (Winter, 1982), which are moderately tolerant to salinity.

Salt tolerance in many nonhalophyte plants is associated with exclusion of sodium and/ or chloride by the roots from the shoot, thus avoiding their accumulation in the leaves. This has been reported for Phaseolus (Jacoby, 1964), Zea mays (Drew and Läuchli, 1985; Yeo et al., 1977), and Trifolium (Winter, 1982). There is also indirect evidence of exclusion mechanisms of toxic ions in citrus (Walker, 1986) and grapes (Kuiper, 1968). 

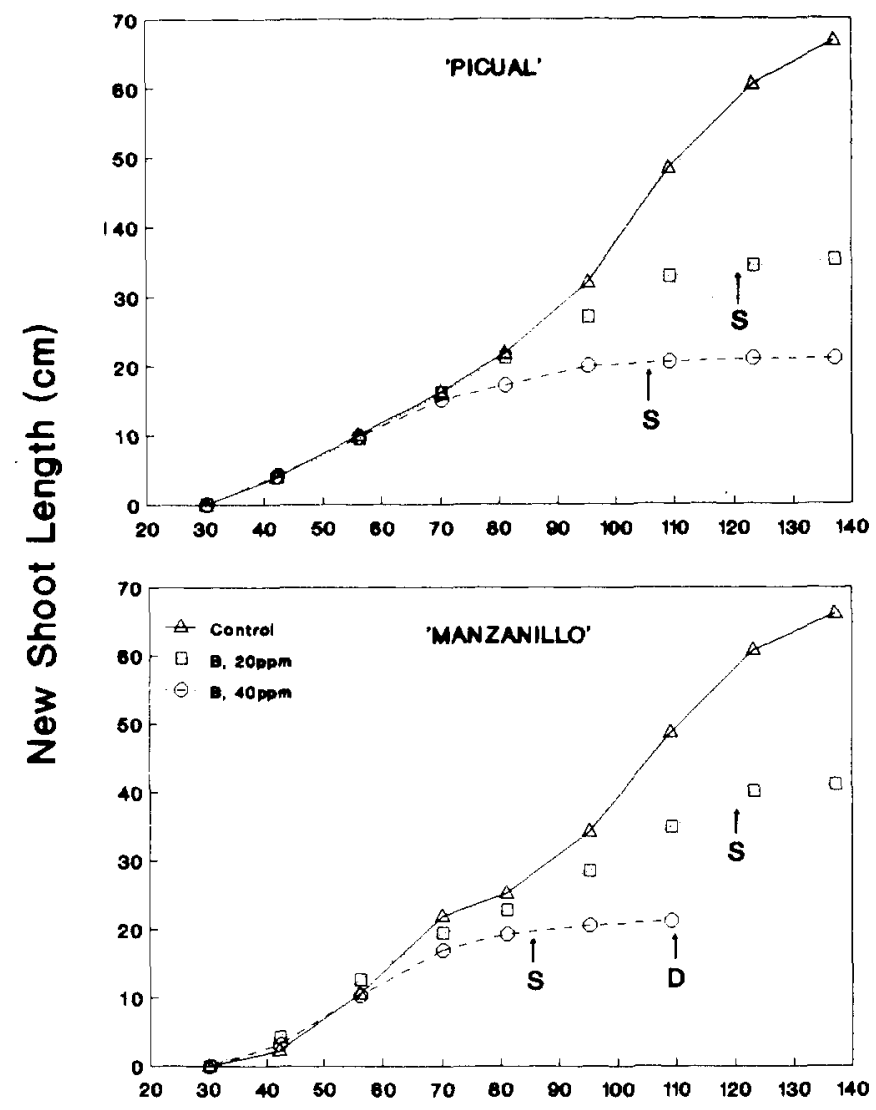

\section{Days after treatment}

Fig. 3. Shoot length of olive cuttings in response to boron concentration in the irrigation water. The symbols indicate: (S) initial symptoms of boron toxicity in the leaves and (D) death of the plant. Each determination is the average of five replications.

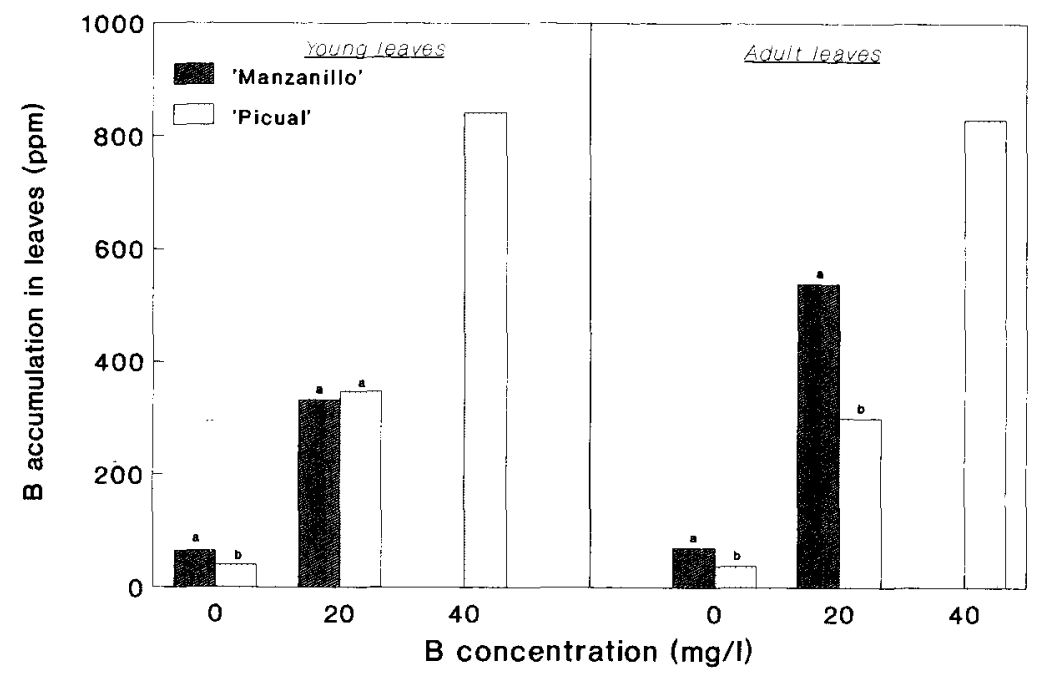

Fig. 4. Effect of boron concentration in the irrigation water on boron accumulation in young and mature leaves of 'Manzanillo' and 'Picual' olive cuttings measured 145 days after the initiation of treatments. Letters indicate differences among cultivars, based on the standard error, within each boron treatment.

In the present work, 'Lechín de Granada' plants grown at 20 and $40 \mathrm{~mm} \mathrm{NaCl}$ showed an ability to restrict the accumulation of sodium in young leaves that was not observed in 'Manzanillo'. This ability to exclude sodium was lost at $100 \mathrm{~mm} \mathrm{NaCl}$, resulting in a clear reduction of shoot growth. These resuits suggest the existence of a sodium ex- were more marked and appeared sooner in 'Manzanillo' than in 'Picual'. Toxic symptoms in mature leaves began with marginal chlorosis that extended to the limb, necrosis appearing mostly on the apical third of the limb area. 'Manzanillo', but not 'Picual', plants treated with B at $40 \mathrm{mg} \cdot$ liter $^{-1}$ died 110 days after the initiation of treatment.

'Manzanillo' had accumulated more boron than did 'Picual' 109 days after the start of the treatments. At that time, the controls for both contained $\approx 40 \mathrm{ppm} \mathrm{B}$; with $\mathrm{B}$ at 20 $\mathrm{mg} \cdot \mathrm{liter}^{-1}$, they contained 160 and $130 \mathrm{ppm}$ $\mathrm{B}$ and with $\mathrm{B}$ at $40 \mathrm{mg} \cdot \mathrm{liter}^{-1}$, the values were 380 and $210 \mathrm{ppm}$, respectively, the differences being significant at $P=0.05$. Also at this time, the first symptoms of leaf toxicity appeared, severely reducing growth of the shoot (data not shown). In 'Manzanillo', toxic symptoms on the leaves and decreased shoot growth had appeared 25 days earlier.

By 145 days after the initiation of treatment (Fig. 4), the 'Manzanillo' plants watered with boron at $40 \mathrm{mg} \cdot$ liter $^{-1}$ had already died. Boron contents of mature 'Manzanillo' and 'Picual' leaves with the $20 \mathrm{mg} \cdot$ liter $^{-1}$ treatment were 540 and $300 \mathrm{ppm}$, respectively (Fig. 4). Boron content of young leaves in this same treatment did not show significant differences between cultivars and were similar to the ones found in the mature 'Picual' leaves.

We have shown that 'Picual' shows greater tolerance to boron excess in the irrigation water than 'Manzanillo'. Likewise, 'Picual' was more susceptible to boron deficit in the medium (unpublished data). This is apparently related to a lower accumulation of boron in 'Picual' leaves. However, boron levels in leaves were similar in both cultivars when toxicity occurred. Thus, a mechanism to avoid high internal levels of boron is more effective in 'Picual' than in 'Manzanillo'.

In many cases, tolerance to salinity in nonhalophyte plants is associated with ionic exclusion mechanisms. The identification and localization of such a mechanism in woody plants would be of great assistance in evaluating the degree of salinity tolerance of these plants.

\section{Literature Cited}

Benlloch, M., I. Moreno, and A. Rodriguez-Navarro. 1989. Two modes of rubidium uptake in sunflower plants. Plant Physiol. 90:939-942.

Bongi, G. and F. Loreto. 1989. Gas-exchange properties of salt-stressed olive (Olea europaea L.) leaves. Plant Physiol. 90:1408-1416.

Drew, M.C. and A. Läuchli. 1985. Oxygen-dependent exclusion of sodium ions from shoots by roots of Zea mays (cv Pioneer 3906) in relation to salinity damage. Plant Physiol. 79:171176.

El-Gazzar, A.M., E.M. El-Azab, and M. Shehata. 1979. Effect of irrigation with fractions of sea water and drainage water on growth and mineral composition of young grapes, guavas, oranges and olives. Alexandria J. Agr. Res. 27:207-219.

Hansen, C.J. 1945. Boron content of olive leaves. Proc. Amer. Soc. Hort. Sci. 46:78-80.

Hartmann, H.T., K. Uriu, and O. Lilleland. 1966. Olive nutrition, p. 252-261. In: N.F. Childers (ed.). Temperate to tropical fruit nutrition. Hor- 
ticultural Publications. Rutgers University, New Brunswick, N.J.

Jackson, M.L. 1958. Soil chemical analysis. Prentice-Hall, Englewood Cliffs, N.J.

Jacoby, B. 1964. Function of bean roots and stems in sodium retention. Plant Physiol. 39:445-449.

Kuiper, P.J.C. 1968. Lipids in grape roots in relation to chloride transport. Plant Physiol. 43:1367-1371.

Lessani, H. and H. Marschner. 1978. Relation between salt tolerance and long-distance trans- port of sodium and chloride in various crop species. Austral. J. Plant. Physiol. 5:27-37.

Maas, E.V. and G.J. Hoffman. 1977. Crop salt tolerance current assessment. J. Irr. Drainage Div. Amer. Soc. Civil Eng. 103:115-134.

Robinson, F.E. 1987. Growth potential of young olive with high chloride irrigation water. HortScience 22:509.

Walker, R.R. 1986. Sodium exclusion and potassium-sodium selectivity in salt-treated trifoliate orange (Poncirus tri.foliata) and cleopatra man- darin (Citrus reticulata) plants. Austral. J. Plant Physiol. 13:293-303.

Winter, E. 1982. Salt tolerance of Trifolium alexandrinum L. II. Ion balance in relation to its salts tolerance. Austral. J. Plant Physiol. 9:227237.

Yeo, A.R., D. Kramer, A. Läuchli, and J. Gullasch. 1977. Ion distribution in salt stressed mature Zea mays roots in relation to ultrastructure and retention of sodium. J. Expt. Bot. 28:1729 